\title{
(MY) THREE PRINCIPLES OF EFFECTIVE ONLINE PEDAGOGY
}

\author{
Bill Pelz, CAS \\ Professor of Psychology \\ Herkimer County Community College
}

\section{INTRODUCTION}

As the recipient of the 2003 Sloan-C award for Excellence in Online Teaching, I have been invited to share some of my thoughts regarding effective online pedagogy. I am nothing if not a teacher, and as such, I am honored-both by the recognition that accompanies this wonderful award, and by the opportunity to share my thoughts about asynchronous teaching and learning with my colleagues.

This may seem a strange way to begin, but I want to admit that my ever-emerging philosophy of education increasingly diminishes the role of "the teacher" in the teaching/learning equation. It took over 30 years of college teaching experience for me to realize that the learner is, for the most part, in charge of what gets learned. Implementing this point of view online has, for me, blurred, somewhat, the distinction between effective teaching and pedagogically sound instructional design. If I create an environment in which a majority of students gladly learn that which they and I deem relevant and salient, then have I succeeded as a teacher or as a designer?_-and does it matter?

I hope some of the ideas that follow are helpful to others. I have liberally interspersed snippets from several of my current online courses throughout this essay. Because screen shots can be hard to read, I have also provided links to the actual courses whenever possible. When no link is available, it's because the course is password protected. Should you find any of the words and/or strategies useful, feel free to copy or adapt them for your own use.

\section{APPLIED ONLINE PEDAGOGY}

\section{A. Principle \#1: Let the students do (most of) the work.}

I took several education courses at SUNY Albany after I began my teaching career at Herkimer County Community College, courses which helped me figure out what it was that I did in the classroom. In one such course I was taught that student 'time-on-task' could account for at least some of the variance observed in much method-comparison research. Boiled down, this means that, regardless of what else is going on, the more 'quality' time students spend engaged in content, the more of that content they learn. This is reasonable. Unfortunately, I was never very successful in putting that bit of insight into practice in the classroom - it ran counter to my "I talk-you listen" style. I slowly came to realize, however, that listening to an enthusiastic and charismatic lecturer such as myself (?) isn't quite the 'quality' time on task that I had convinced myself it was. One of my education professors put it this way: "A lecture is the best way to get information from the professor's notebook into the student's notebook without passing through either brain." My transition from "sage on the stage" to "guide on the side" has been gradual but rather complete. Here are a few of the strategies I use for putting the students in charge of their own learning. 
1. Student Led Discussions: Student led discussions are a major learning activity in all of my 'reading' courses: Introductory Psychology, Developmental Psychology, Social Psychology and Abnormal Psychology. To a somewhat lesser extent, I also use student led discussions in my 'skill' courses: Freshman Seminar, Statistics for the Social Sciences, and Experimental Psychology.

Introducing the concept of the student led discussion to students, many of whom are used to listening to classroom discussions, or lurking in online discussions, takes place in a sequence of ungraded "Icebreaker Activities”.

Icebreaker Activity 1. Introduce the idea that 'questions are a learning tool'. I refer students to a website which they are to read and then discuss among themselves.

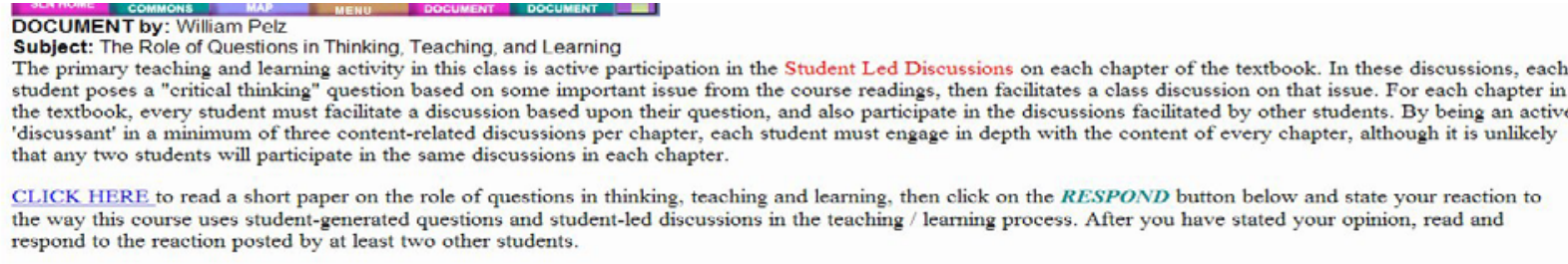

Icebreaker Activity 2. Introduce the idea of students as discussion facilitators.

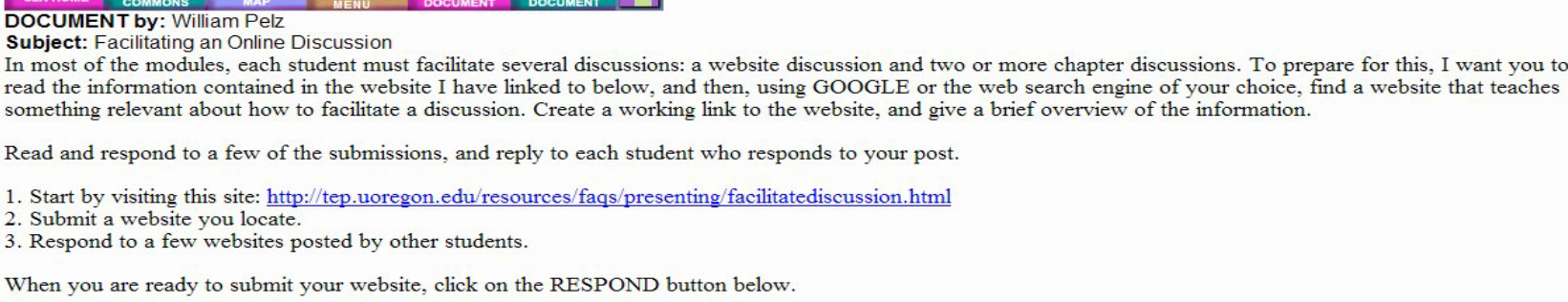

Many of the professors I talk with are skeptical of putting students in charge of covering the content of the course. I, too, was initially skeptical. I have been pleasantly surprised at how well and how rapidly my students have learned how to facilitate discussions. They quickly realize that it is in their best interest to select important and multidimensional issues to discuss. They become quite adroit at asking thoughtprovoking questions which can not be answered by looking some facts up in the book. 
Icebreaker Activity 3. Give detailed instructions to get the student led discussions off on the right foot.

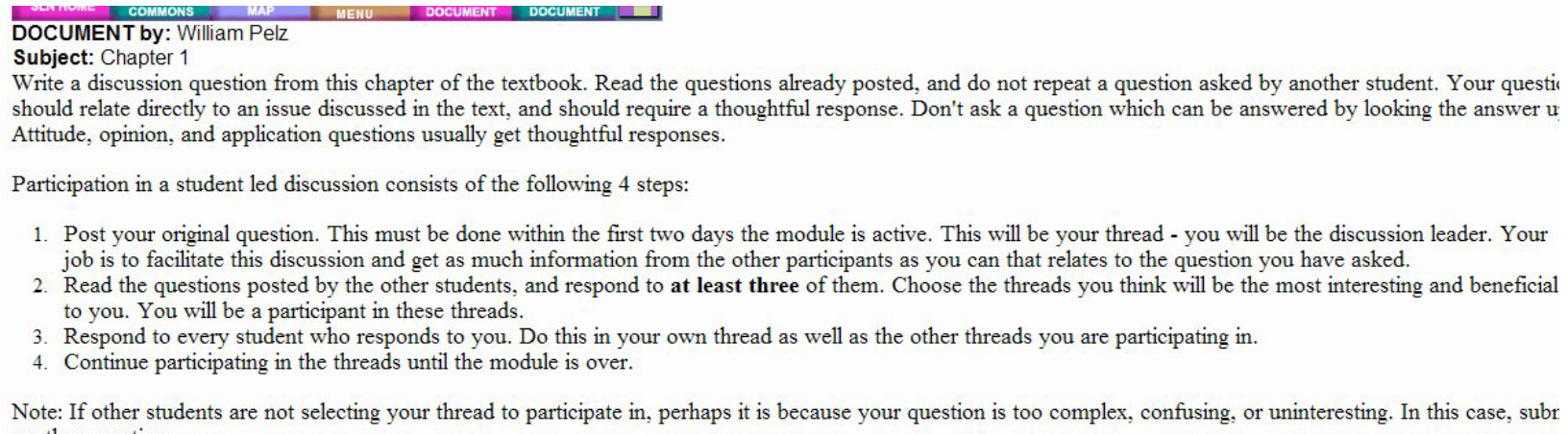

1. Post your original question. This must be done within the first two days the module is active. This will be your thread - you will be the discussion leader. Your job is to facilitate this discussion and get as much information from the other participants as you can that relates to the question you have asked.

2. Read the questions posted by the other students, and respond to at least three of them. Choose the threads you think will be the most interesting and beneficial to you. You will be a participant in these threads.

3. Respond to every student who responds to you. Do this in your own thread as well as the other threads you are participating in.

4. Continue participating in the threads until the module is over.

Note: If other students are not selecting your thread to participate in, perhaps it is because your question is too complex, confusing, or uninteresting. In this case, subr another question.

When you are ready to post your question, click on the Respond graphic link below.

What can you expect to achieve from the student led discussions? That is a reasonable question, and the answer may surprise you. My students are freshmen or sophomores at an open door community college. They quickly learn to ask thought-provoking questions which address the salient issues presented in the textbook. The ensuing discussions are usually both focused and far-reaching, depending upon my guidance and feedback. I encourage you to judge for yourself the quality of discourse that occurs by browsing through the SUNY Learning Network's course for observation. The link to this course is on the SLN Homepage at http://sln.suny.edu. (Most of the strategies I will be presenting are present in this course.)

2. Students Find and Discuss Web Resourses: This is a recurring assignment. In each module, students locate a website which deals with content relevant to the chapters currently being discussed. They write a brief (400+ words) overview/review of the website, and then facilitate a discussion on it.

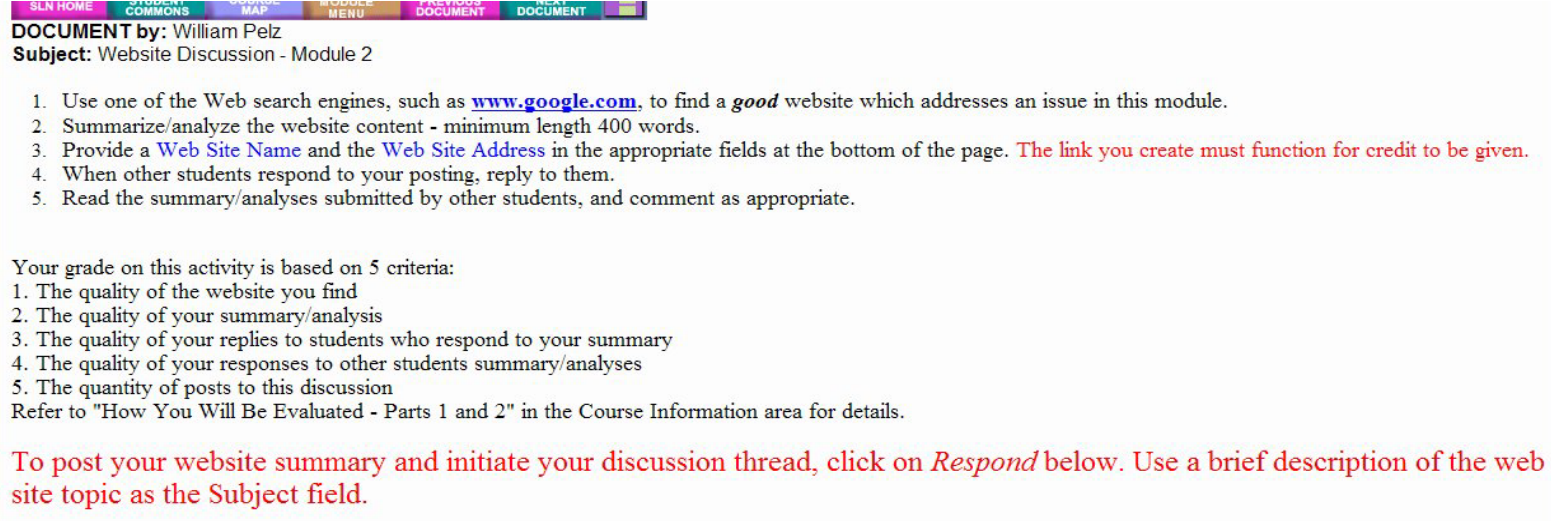

This activity provides students practice with the skills they need to locate discipline appropriate web resources, and gives them some practice in evaluating the authenticity of such sites. Additionally, students are exposed to additional and often newer information than that presented in their textbook. 
3. Students Help Each Other Learn (Peer Assistance): This strategy works well in courses which require students to solve problems or complete lab activities, such as math courses, science courses, etc. The directions below are from my Statistics for the Social Sciences course.

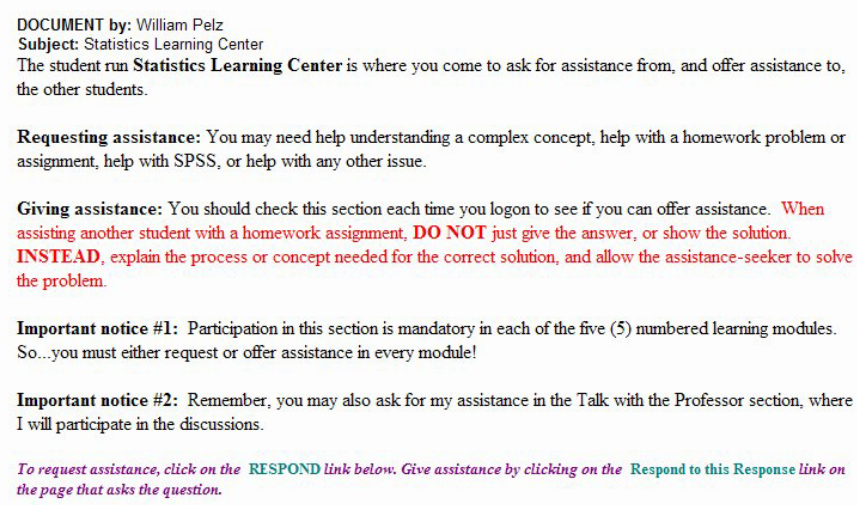

4. Students Grade Their Own Homework Assignments: This strategy works well in courses where homework problems are assigned. Students submit their solutions to the professor, and then check their answers against the key. They discuss with one another the errors they made, then suggest their grade for the assignment to the professor. Here are the instructions I post for my Statistics course:

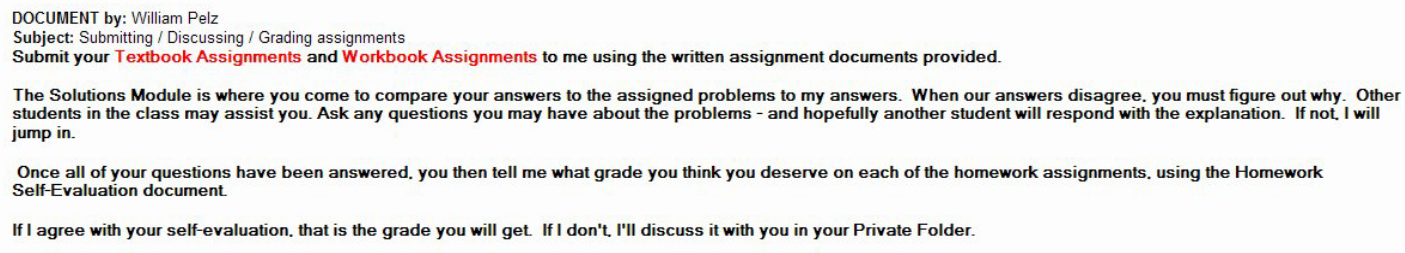

5. Case Study Analysis: I find this strategy very effective in my Abnormal Psychology course. Students are given fairly complex cases to discuss. Following the discussion phase, each student must formulate a diagnosis, prognosis, and treatment program. They are allowed to collaborate on their reports, but each student receives an individual grade. 


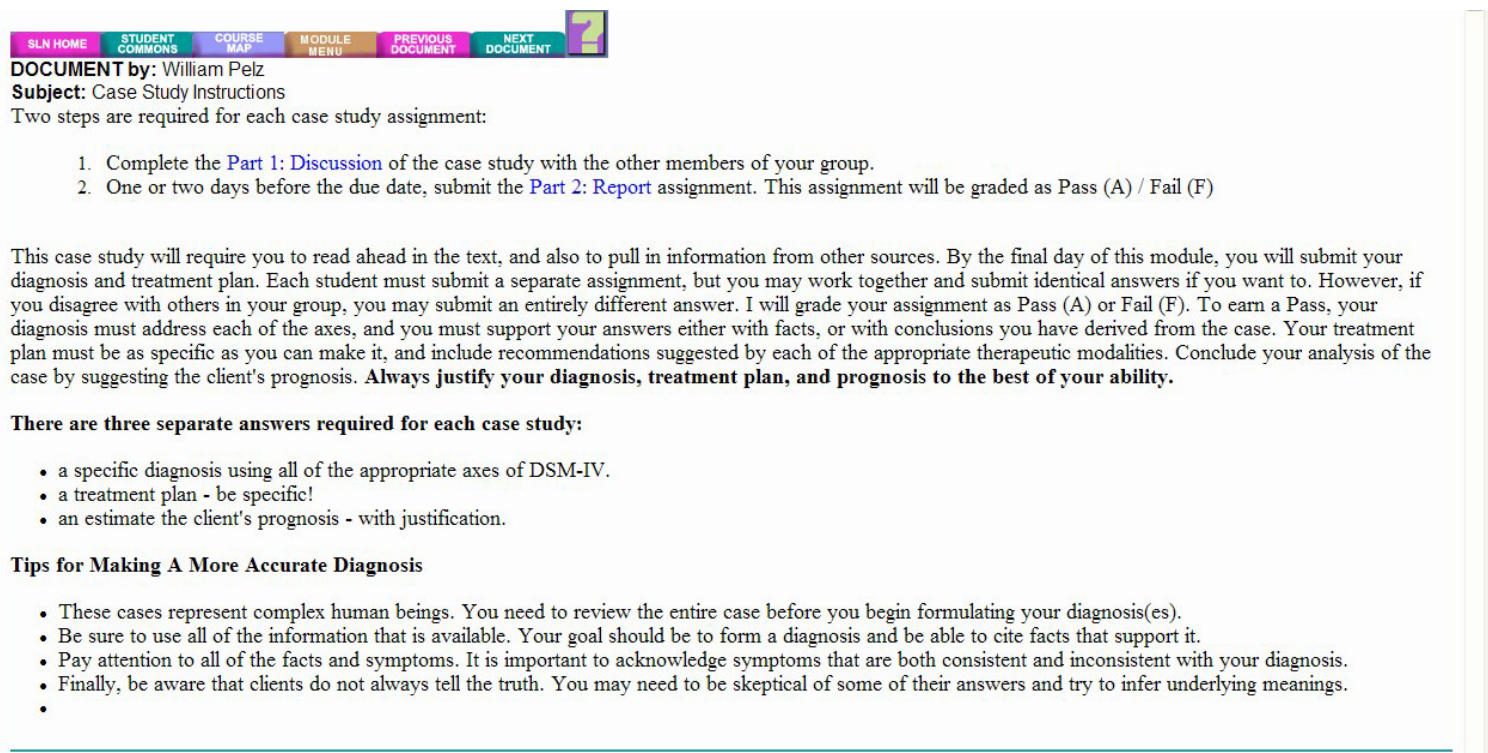

The common thread in each of these learning activities is that the students do most of the work. The role of the professor is limited to providing the necessary structure and directions, supportive and corrective feedback, and evaluation of final product.

In the case of the student led discussions, evaluation is no small matter! I grade each discussion response using a grading scale and rubric well-known to the students. (I introduce and discuss this rubric later.) Students receive feedback from me within 24 hours of submitting their discussion posts. This requires me to logon and grade the new discussion posts every day. This may sound overwhelming - it is not. Grading student posts in a discussion-heavy online course with 25 students requires about 30-45 minutes per day. It does not take me any longer to manage a full load of online courses than it would tale me to manage the same load in the traditional classroom environment.

\section{B. Principle \#2: Interactivity is the heart and soul of effective asynchronous learning.}

I believe that interactivity is what differentiates an effective online course from a high-tech correspondence course. Research conducted by the SUNY Learning Network since it's inception in 1995 has consistently identified quantity and quality of student-student and student-professor interaction as strong positive correlates with student and faculty satisfaction. Face-to-face interactivity is good, threaded asynchronous interactivity is great! In a traditional classroom, interaction requires listening and talking, online interactivity requires reading and writing. In my experience and opinion, reading and writing are superior to listening and talking for learning. Do I have any empirical evidence to support this belief? No, but I think it's true! I know from the feedback I get from my online students that they like threaded discussions of content, and they tell me that they are learning a lot from them. I get similar reports fairly often from acquaintances who teach online.

Interaction is not just discussion. Students can be required to interact with one another, with the professor, with the text, with the Internet, with the entire class, in small groups or teams, one-on-one with a partner, etc. In addition to discussing the course content, students can interact regarding assignments, problems to solve, case studies, lab activities, etc. Any course can be designed with required interactivity. Here are a 
few examples from my courses.

1. Collaborative Research Paper: Students collaborate to develop topics, organize their paper, and collect web resources. The completed paper is submitted for class discussion.

Step 1: Assign the term paper at the beginning of the semester.

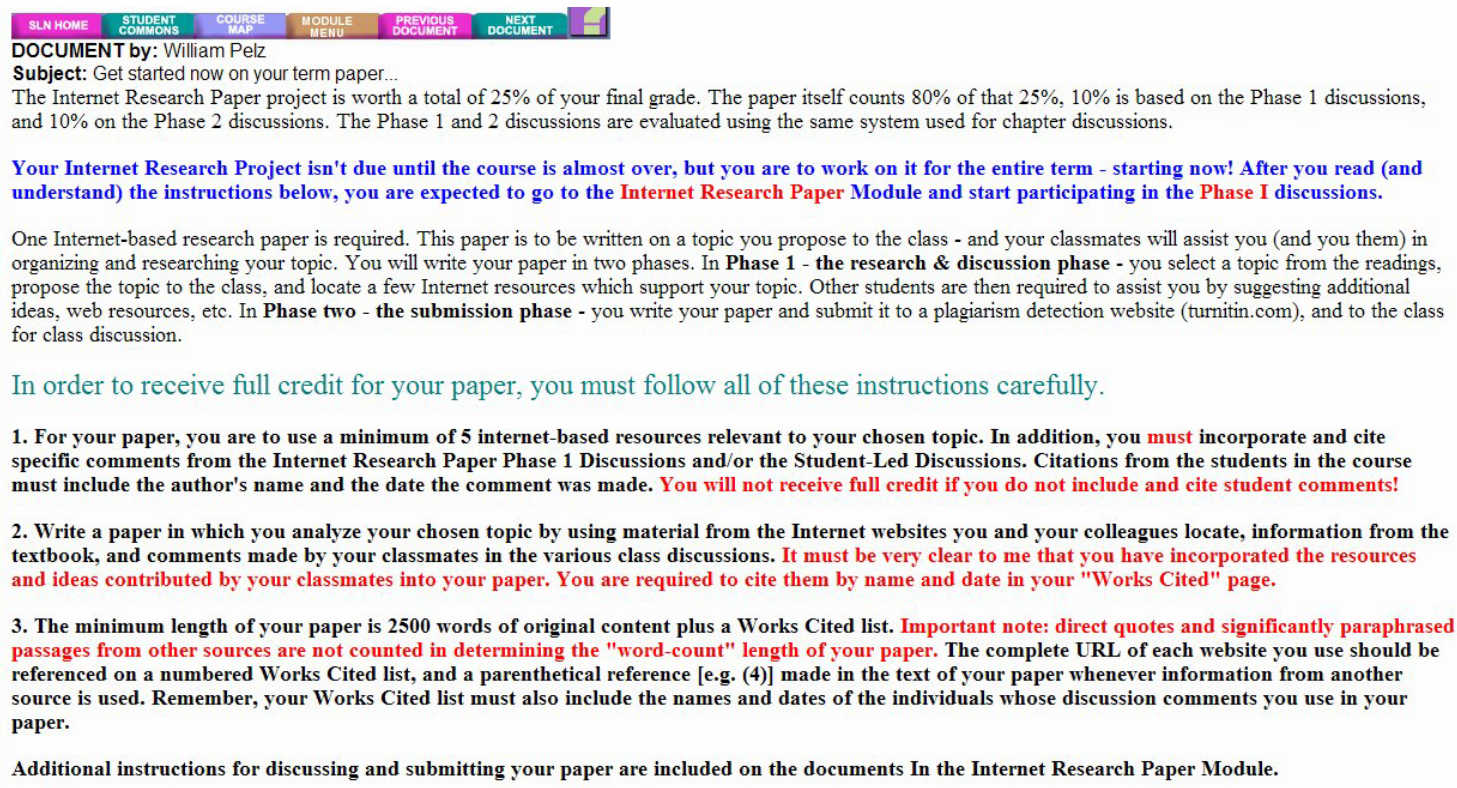


Step 2. Students discuss their research ideas, develop a topic, and accumulate resources in the Phase 1 Discussions.

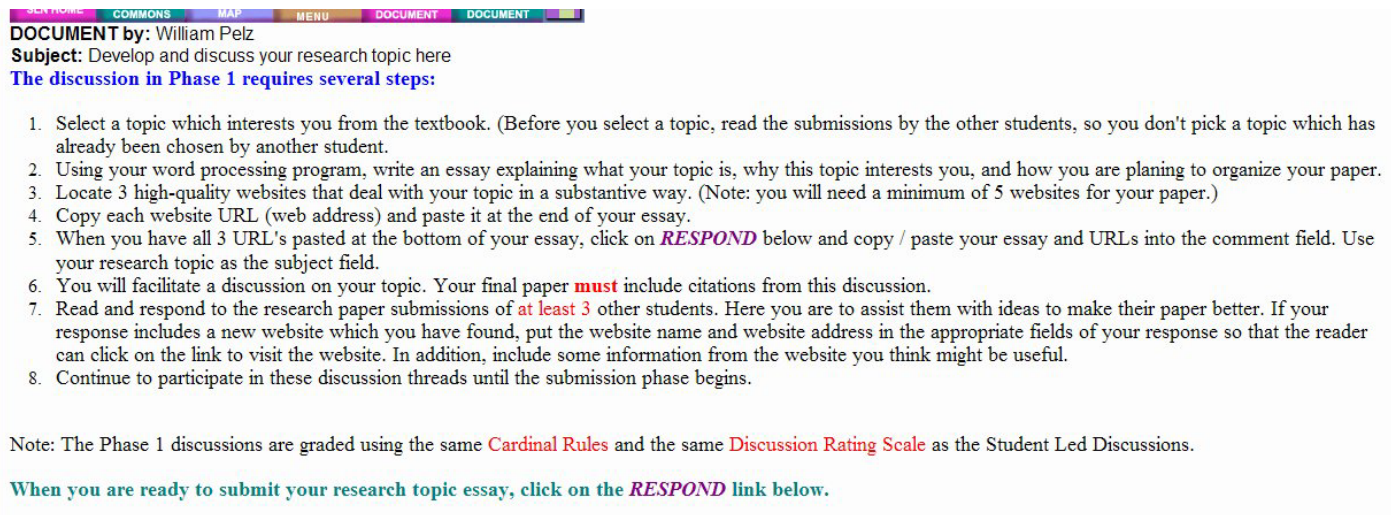

Step 3. Students submit their finished paper for class discussion.

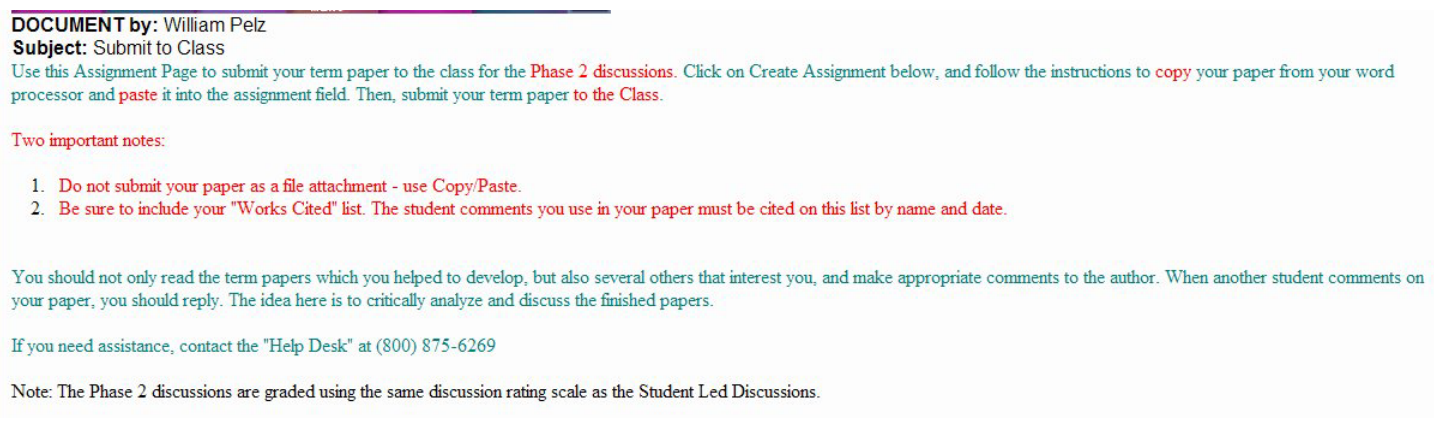

The collaborative research paper assignment not only satisfies the "interaction" requirement, but it also provides each student with access to additional detail and information on a wide variety of issues that have been discussed throughout the semester. 
2. Research Proposal Team Project: This is similar to the collaborative research paper, but adapted for a 'skills' course-in this case Experimental Psychology.

Step 1. Explain the assignment.

The Nature and Scope of the Term Project - Lotus Notes
PocumENT by: William Pelz
The term project requirement is to write a research proposal and defend it in front of a project review panel.
Phase 1: You are to work collaborativelly in Phase 1 to create your research idea, background information, research question(s), experimental design, and analysis. This phase will begin on day
one of the course and continue until Module 6 begins. The 2 goals of Phase 1 are:
1. Through individual effort and collaboration with other students, develop a defensible research proposal for yourself.
2. Assist the other students with the development of their research proposals.
Phase 2: In Phase 2 you will write your research proposal using the APA style guidelines, save it in Rich Text Format (RTF), then submit it to a plagiarism detection site AND to a "Review
Panel" for critical analysis and discussion. The "Review Panel" is composed of classmates, and you will be required to present your proposal to the panel, answer all of their questions, and
respond to all of their suggestions and criticisms. In addition, you will sit on a "Review Panel" which will be reviewing several research proposals. You are expected to critically review the
proposals and to offer suggestions for improving them.

Step 2: Students select a research topic and collaborate with others to collect resources.

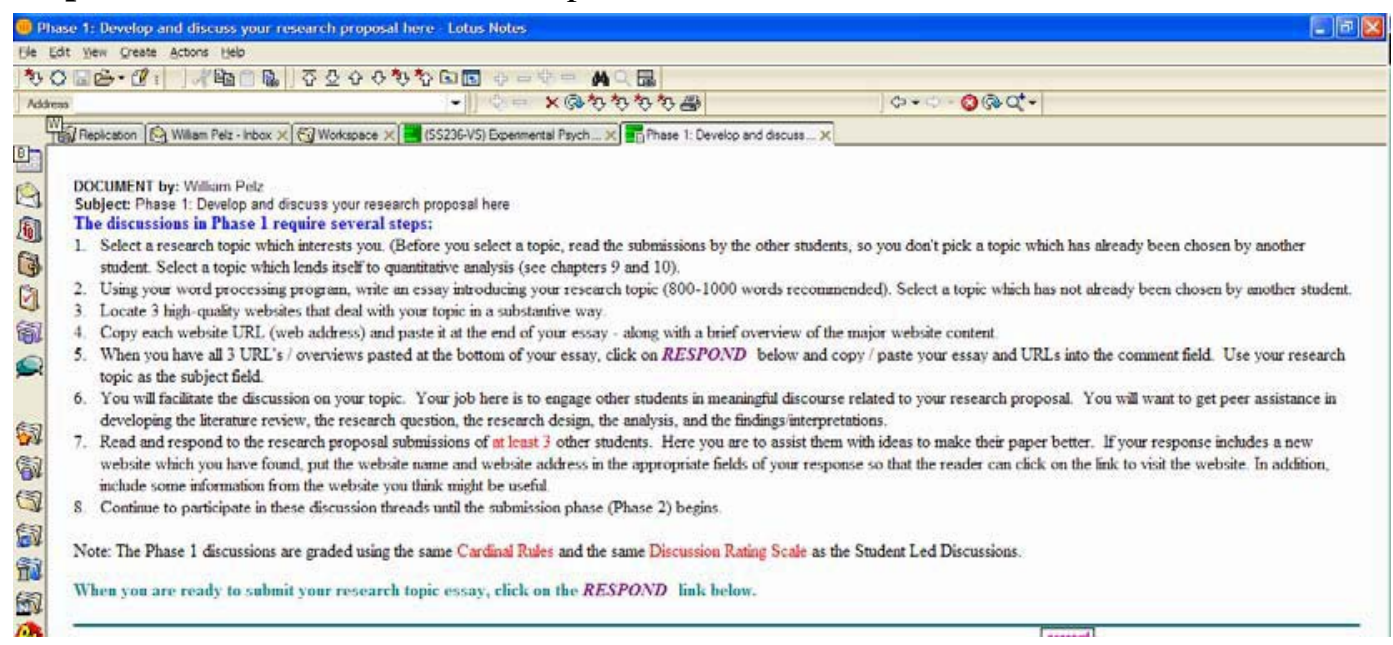


Step 3. Submit the research proposal to a 'team' for review and comment. Each student must not only submit her/his own research proposal, but must also be a 'reviewer' for the other proposals submitted by team members.

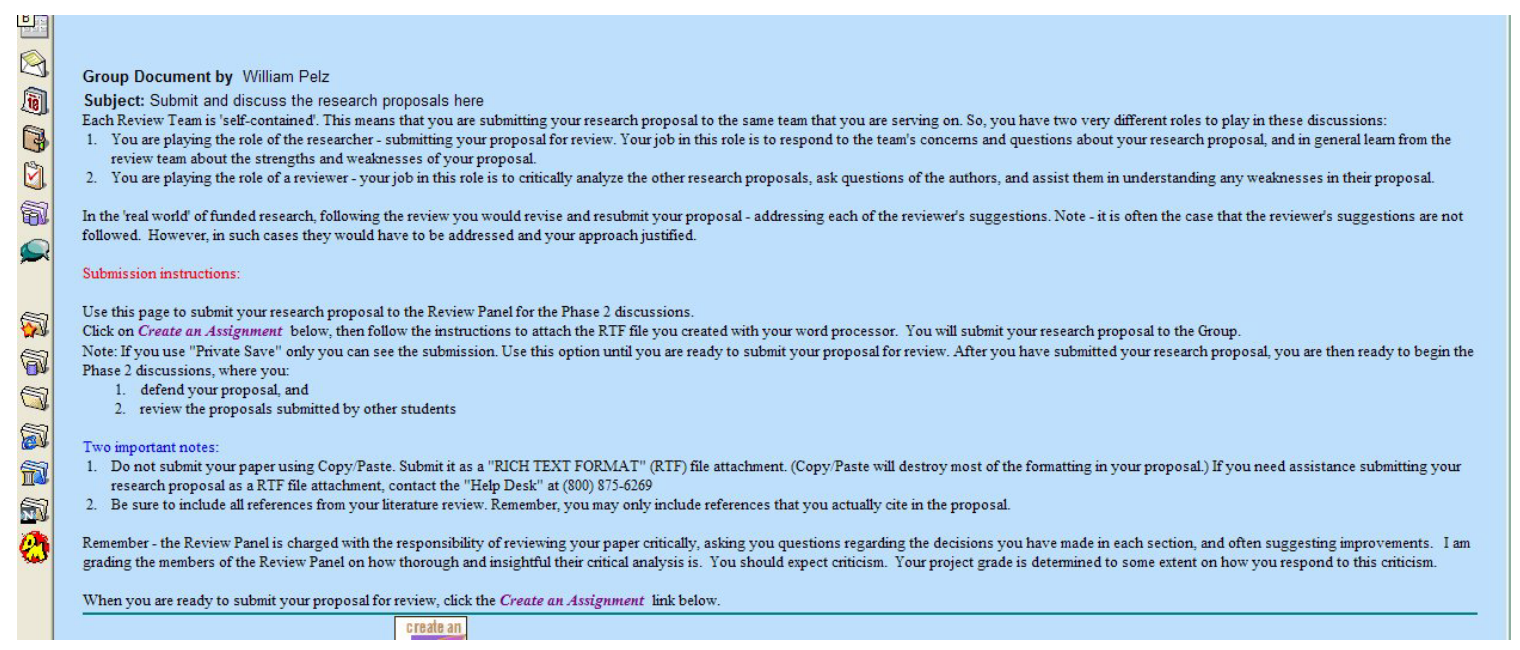

\section{Principle \#3: Strive for presence.}

Recent research in the field of online learning suggests that discussion responses that add value to a discussion fall into one or more of three categories: Social Presence, Cognitive Presence, or Teaching Presence [1].

Social Presence: When participants in an online course help establish a community of learning by projecting their personal characteristics into the discussion - they present themselves as "real people." There are at least three forms of social presence:

- Affective - The expression of emotion, feelings, and mood

- Interactive - Evidence of reading, attending, understanding, thinking about other's responses

- Cohesive - Responses that build and sustain a sense of 'belongingness', group commitment, more common goals and objectives

Although much has been written on the difficulty of creating a shared community of learning online, in my experience that just isn't so. In general, I find that online students bond earlier and 'better' than students sitting in the same classroom. To some extent, this is probably because they aren't sitting sideby-side. There is an absence of appearance-based factors that can inhibit self expression and create stereotypical expectations. Further, possibly because of the anonymity of the asynchronous mode, online students tend to self-disclose to a greater extent than those sitting face-to-face.

There are a few formal techniques that promote collegiality. I require that students introduce themselves as an initial condition of participating in the course. This breaks the ice and provides some points of reference for identifying who a student is and where s/he is coming from. I also provide a couple of forums for interpersonal interaction not related to the content of the course. One such forum is called the Bulletin Board, where any class member, including the professor, can post an announcement or pose a question. Students frequently use this area to discuss personal issues, such as "Where are you from?" and 
"What's it like at your college?" Another forum I provide is called "Asynchronous Chat Rooms.” The example below is from the course specified for public observation by the SUNY Learning Network [2].

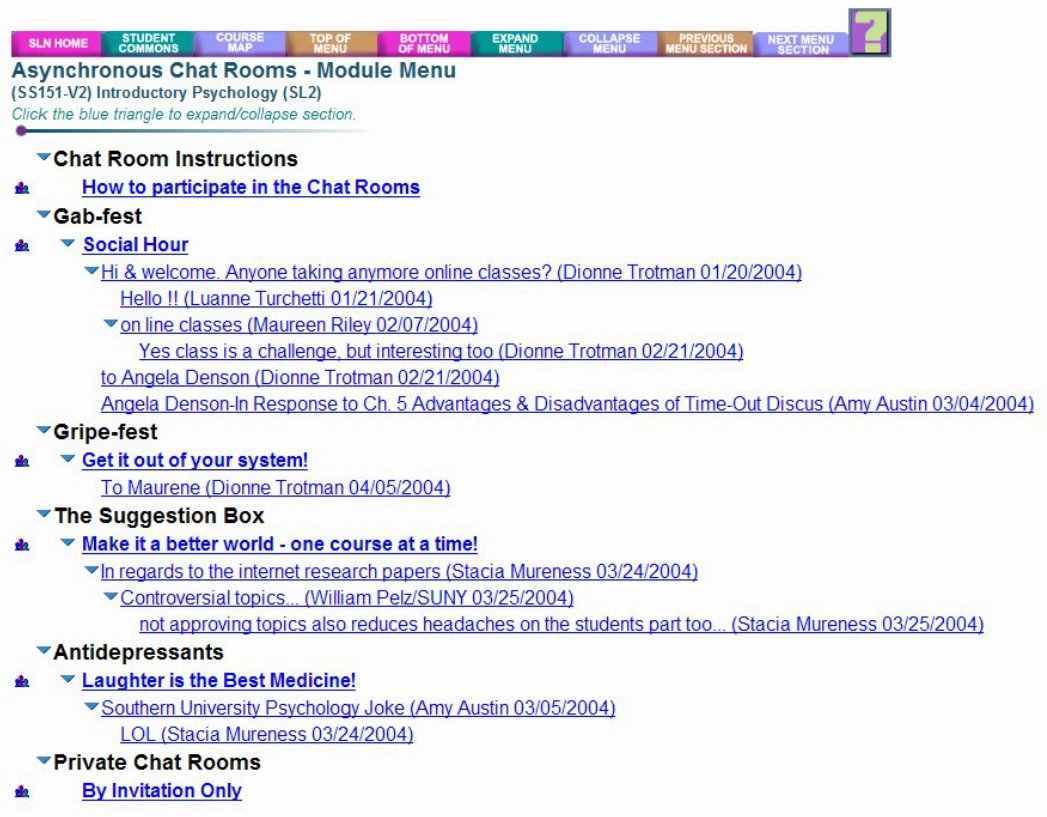

Cognitive Presence: The extent to which the professor and the students are able to construct and confirm meaning through sustained discourse (discussion) in a community of inquiry.

- Cognitive presence can be demonstrated by introducing factual, conceptual, and theoretical knowledge into the discussion.

- The value of such a response will depend upon the source, clarity, accuracy and comprehensiveness of the knowledge.

Student led discussions are a major learning activity in most of my online courses. These discussions provide a great opportunity for students to present to one another the important information that constitutes formal study in the discipline. Of course, for academic authenticity and integrity, the information provided in the student submissions must be both accurate and comprehensive. I treat each discussion submission as if it is an answer to a test question-and I grade it using a rubric which I share with the students in the course syllabus documents they have access to at all times. 


\section{The Discussion Rubric:}

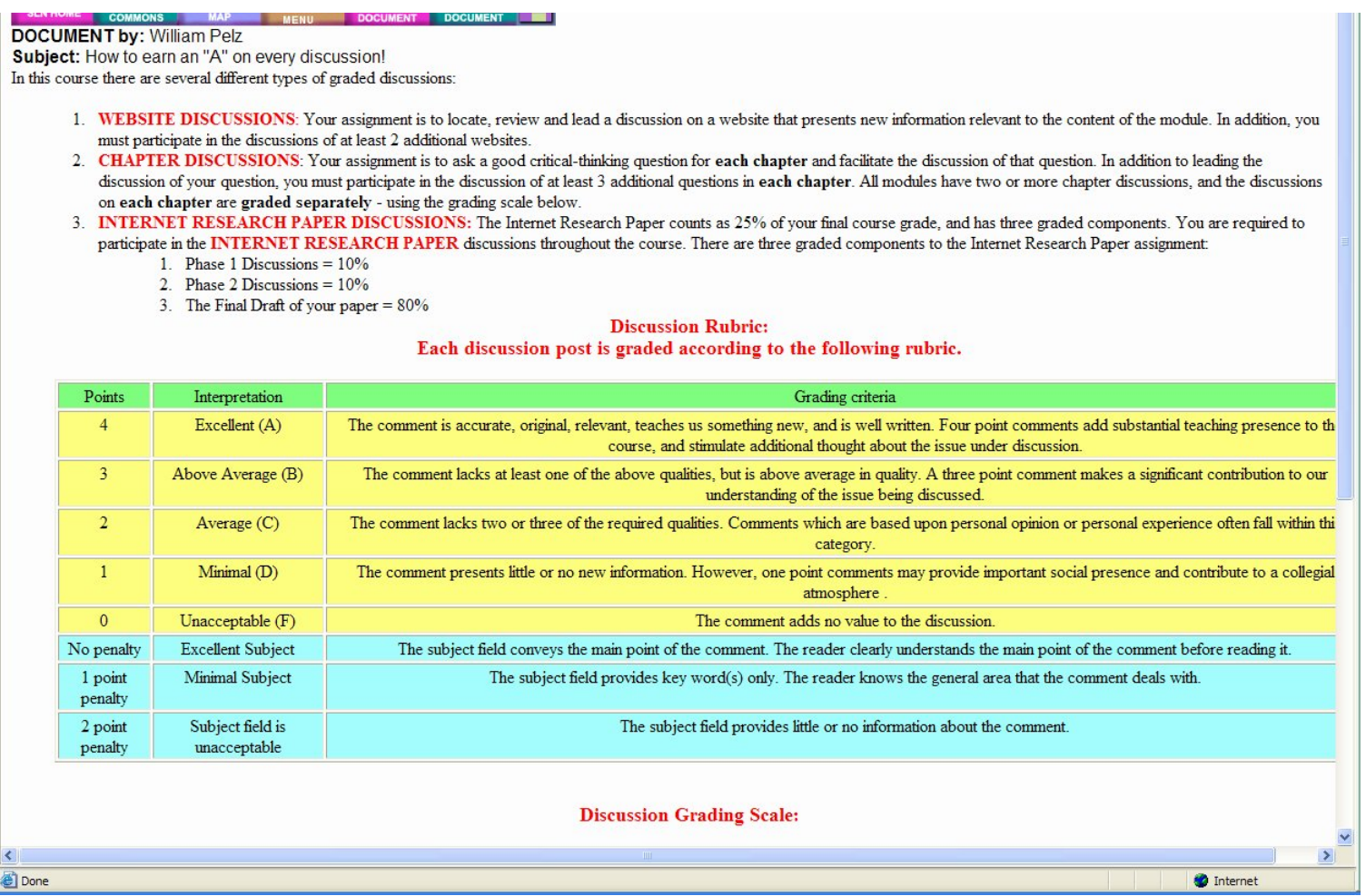

Each student asks an 'original (non-duplicated) question, then facilitates the discussion on that question, for every chapter. With around 25 students in a course, this usually satisfies the 'comprehensive coverage of the discipline' issue. The previously discussed instructions, along with this rubric, address the 'accuracy' issue. The final component of the student-led discussion strategy is to apply a grading scale to the discussions. Students are given daily feedback on their discussion post grades, and can judge their progress and manage their time on the course accordingly.

\section{The Discussion Rating Scale:}

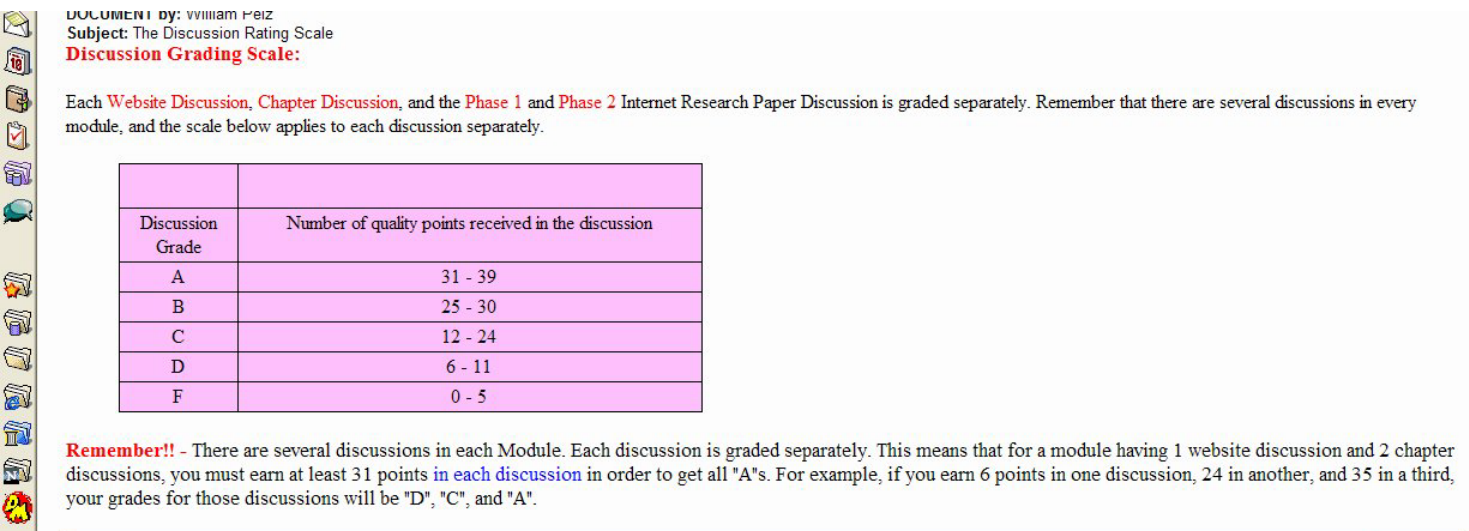


Teaching Presence: Defined: "Teaching presence is the facilitation and direction of cognitive and social process for the realization of personally meaningful and educationally worthwhile learning outcomes [1].” There are two ways that the professor and the students can add teaching presence to a discussion:

1. By facilitating the discussion:

a. Identifying areas of agreement and disagreement

b. Seeking to reach consensus / understanding

c. Encouraging, acknowledging and reinforcing student contributions

d. Setting a climate for learning

e. Drawing in participants / prompting discussion

f. Assessing the efficacy of the process

2. By direct instruction:

a. Presenting content and questions

b. Focusing the discussion

c. Summarizing the discussion

d. Confirming understanding

e. Diagnosing misperceptions

f. Injecting knowledge from diverse sources

g. Responding to technical concerns

Striving for cognitive, social, and teaching presence has consumed much of my course development attention of late. To my delight and gratification, I have discovered that it is both possible and desirable to merge this principle with the other two. Students, through appropriately designed interactive assignments, can assist the professor in providing ample quantities of all three 'presences' in an asynchronous online environment.

The “Two Cardinal Rules" of Discussion: Several years ago, while browsing through a threaded discussion, I noticed that the 'subjects' my students were creating for their discussion posts were not usually very informative. I had an epiphany! The subject field of a discussion post, which becomes the web link to the discussion post, should provide an "advance organizer" for the comment the student is making. When I, or another student, read the subject of a discussion post, it should get me (us) mentally prepared for the discussion comment. With this in mind, I created the "Two Cardinal Rules": 


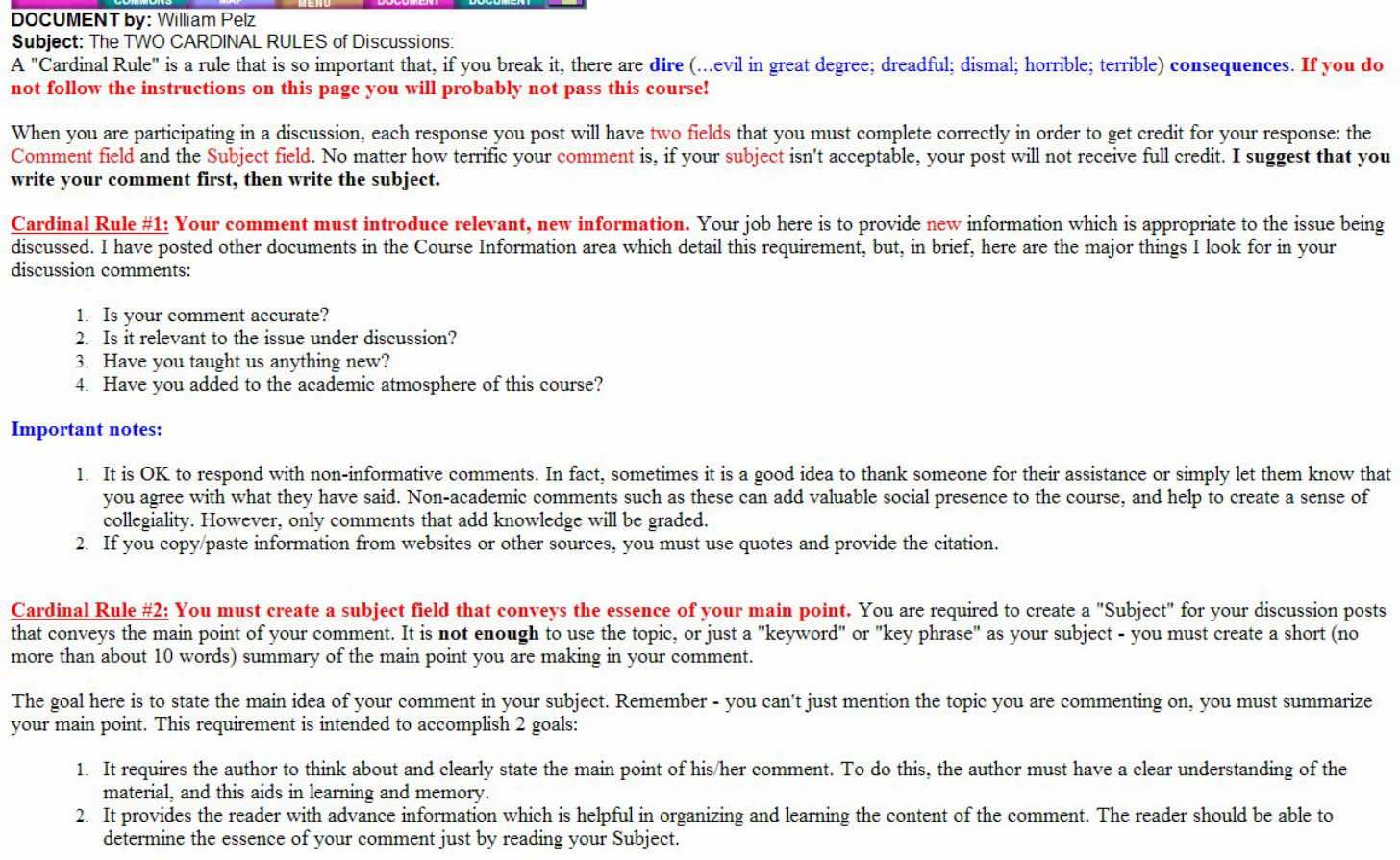

Cardinal Rule \#2: You must create a subject field that conveys the essence of your main point. You are required to create a "Subject" for your discussion posts that conveys the main point of your comment. It is not enough to use the topic, or just a "keyword" or "key phrase" as your subject - you must create a short (no more than about 10 words) summary of the main point you are making in your comment.

The goal here is to state the main idea of your comment in your subject. Remember - you can't just mention the topic you are commenting on, you must summarize your main point. This requirement is intended to accomplish 2 goals:

1. It requires the author to think about and clearly state the main point of his/her comment. To do this, the author must have a clear understanding of the material, and this aids in learning and memory.

2. It provides the reader with advance information which is helpful in organizing and learning the content of the comment. The reader should be able to determine the essence of your comment just by reading your Subject.

\section{ACKNOWLEDGEMENTS}

Yes, I am proud of my contributions to online pedagogy, I think my online courses are good, and I humbly accepted the Sloan-C award. But it would be ludicrous for me to take credit for any of the strategies, techniques, or innovations I have presented and discussed in this article. My so-called innovations are the direct result of my association with the incredible professionals at the SUNY Learning Network, Peter Shea, Alexandra Pickett, Erik Fredericksen (now at Cornell) and Karen Swan (now at Kent State). Our late-night, often heated discussions over student, faculty, and course management issues provided much-needed clarification for my sometimes too narrow understanding of asynchronous higher education.

\section{REFERENCES}

1. Garrison, D.R., Anderson, T., and Archer, W. Critical Inquiry in a Text-Based Environment: Computer Conferencing in Higher Education. The Internet and Higher Education 2(2-3): 1-19, 2000.

2. Observe a course: http://sln.suny.edu.

\section{ABOUT THE AUTHOR}

Bill Pelz is Professor of Psychology at Herkimer County Community College. He joined the faculty of HCCC in August of 1968, the second year the college was in operation. During his 36 year tenure at HCCC he has served as Chair of the Humanities and Social Science Division and Director of Distance Learning, but has always returned to his first love - teaching. In 1994 he was presented with the SUNY Chancellor's Award for Excellence in Teaching, and in 2003 the Sloan-C Award for Excellence in Online Teaching - most cherished prizes. Bill has published an odd assortment of scholarly and academic articles, most recently focused on the area of student and faculty satisfaction with asynchronous teaching and learning. His current research interest is in isolating the pedagogical factors which influence student 
achievement in virtual learning environments. In addition to teaching full-time on the Internet, Bill is also the Coordinator of the HCCC Internet Academy, the HCCC Campus Instructional Design Specialist, and the Lead Trainer for the SUNY Learning Network, having trained in excess of 1000 SUNY faculty during the past five years. He currently represents The State University of New York in the discipline of Psychology on the national Merlot Project, which is assembling a collection of high quality web-based learning objects for use in higher education. 